\title{
Revisiting Wittgenstein on the Nature of Religious Language
}

\author{
Kevin Kimble \\ Department of Philosophy, National Chung-Cheng University \\ 168 University Road, Min-Hsiung, Chia-Yi, Taiwan 621 \\ Tel: 886-5-272-0411 ext. 31422 E-mail: kekimble77@yahoo.com
}

\begin{abstract}
In his Lectures on Religious Belief, Wittgenstein presents us with a view of the nature of religious discourse according to which religious claims are non-cognitive and not verifiable or assessable for correctness by means of evidence. I argue that, contrary to what is implied in $L R B$, these features do not follow from an analysis of the language game of religion, given that such an analysis is carried out on Wittgenstein's own terms. A natural suggestion is that his assessment of the status of religious language is guided in part by implicit acceptance of a verification criterion of meaning held independently of any analysis of language games. While Wittgenstein could thereby combine his view of language games and his use theory of meaning with this verification condition in assessing the meaning of religious statements, such a move comes at considerable philosophical cost.
\end{abstract}

Keywords: Wittgenstein, Religion, Religious language, Language game, Verification, Meaning, Non-cognitivism

\section{Introduction}

The ideas set forth in Ludwig Wittgenstein's later philosophy have far-reaching implications for a wide variety of issues in philosophy of religion, issues which have been at the forefront of much recent discussion. One area which has suffered serious neglect is the question of the relationship between Wittgenstein's all-important notion of language games and his treatment of the genuine character of religious belief. Various passages in the Philosophical Investigations and in his Lectures on Religious Belief shed considerable light on this question. Here is my plan for what follows. In the first section, I briefly expound one of the central tenets of Wittgenstein's theory of meaning, (Note 1) namely his notion of language games. In section II, I briefly outline three essential features of religious discourse which Wittgenstein sets out in the Lectures. In the final section, I argue that two of these features do not follow from an analysis of the language game of religion, given that such an analysis is carried out on Wittgenstein's own terms. A natural suggestion is that his assessment of the status of religious language is guided in part by implicit acceptance of a verification criterion of meaning held independently of any analysis of language games. After highlighting a logical tension between these two components of Wittgenstein's overall theory of meaning as applied to religious discourse, I suggest one plausible way of resolving the tension, although the proposed reconciliation comes at considerable philosophical cost.

\section{Wittgenstein's Theory of Language}

\subsection{Language Games}

The view of language and meaning which Wittgenstein develops in the Philosophical Investigations may be generally expressed as the view that language is a complex of language games that are logically distinct from one another, and yet interdependent: "I shall call the whole, consisting of language and the actions into which it is woven, the language game." (Note 2) In order to know what the meaning of a word or sentence is, one should not ask what it "pictures" but rather what job or task it performs. One of Wittgenstein's most famous illustrations of a simple language game involves a situation with a builder and his helper:

A is building with building-stones: there are blocks, pillars, slabs, and beams. B has to pass the stones, and that in the order in which A needs them. For this purpose they use a language consisting of the words "block," "pillar," "slab," and "beam." A calls them out; B brings the stones which he has learnt to bring at such and such a call. Conceive this as a complete primitive language. (Note 3 )

B will not automatically understand what A means. He must learn how to use the words and sentences in certain ways, that is, he must be trained in certain prior activities before he can even begin to understand the orders given by A. He must grasp, for example, what naming is, what it means to ostensibly define something by 
pointing to it, what certain names (e.g., "slab") refers to, and what to do when A calls out the order. Thus, in order to learn the meaning of this particular exercise, the sentences uttered and the surrounding behavior and activities must be seen as an interwoven series of linguistic and non-linguistic movements, and Wittgenstein likened this to playing a game:

We can also think of the whole process of using words as one of those games by means of which children learn their native language. I will call these games "language games" and will sometimes speak of a primitive language as a language game. And the processes of naming the stones and repeating words after someone might also be called language games. Think of much of the use of words in games like ring-a-ring-a-roses. I shall also call the whole, consisting of language, and the actions into which it is woven, the "language game." (Note 4)

Wittgenstein says that there are countless kinds of sentences and utterances which make up language games, and countless different uses of words and sentences. Some examples include describing an object, reporting an event, forming and testing a hypothesis, telling jokes, making up a story, and play-acting. Each different kind of sentence and language game presupposes certain rules for how the language is used and understood, just as a game of chess can not be understood and played unless there are appropriate rules for describing how the game is to be played and is to proceed. (Note 5) Discovering the meaning of language is much like understanding a game by watching it being played and inferring the rules inductively.

The acquisition and use of language includes both verbal and non-verbal behavior, and any given linguistic expression is itself but one element in a whole nexus of activity which occurs in a context. It is this complete activity that Wittgenstein terms a "form of life." (Note 6) People who use different language games are participating in different forms of life which have no essential relationship to one another. While various words, expressions, or sentences may appear in several language games, this does not mean that what one is doing with them in one language game is the same thing she is doing with them in another. Each language game is logically distinct from every other. Wittgenstein claims that just as there is no necessary feature common to all games, so neither is there anything essentially common to all language games. What gives unity to all those activities which constitute various language games is a multitude of relationships "overlapping and criss-crossing", analogous to the family resemblances that can often be observed among several generations of the same family. (Note 7)

\subsection{Use Theory of Meaning}

If the exact same words and sentences can belong to different language games, then what distinguishes their meaning in one language game from their meaning in another? Wittgenstein's answer is his use theory of meaning: the meaning of a word, expression, or sentence depends upon its particular employment or application in a given language game. An utterance in one language game means something quite different from the same utterance or sentence in another language game. "For a large class of cases-- though not for all-- in which we employ the word 'meaning' it can be defined thus: the meaning of a word is its use in the language." (Note 8) Wittgenstein likens words and sentences to tools with which one can make particular moves in a language game:

Think of the tools in a tool box: there is a hammer, pliers, a saw, a screw-driver, a rule, a glue-pot, glue, nails and screws. The functions of words are as diverse as the functions of these objects. (And in both cases there are similarities.) Of course, what confuses us is the uniform appearance of words when we hear them spoken or meet them in script and print. For their application is not presented to us so clearly. (Note 9)

In order to know the meaning of a sentence one should not ask what it "pictures" but rather what job or task it performs. Wittgenstein employs the concept of "guiding" as a further illustration of his thesis. One can imagine innumerable situations where the expression "being led by the hand" (or the behavior described by the expression) might mean completely different things. Such an activity could describe being led across a playing field blind-folded, being led somewhere by force, being led by a partner in a dance, or taking a walk with an intimate friend. These and other examples highlight the anti-essentialist theme found in Wittgenstein's later philosophy which emphatically rejects the teaching of the Tractatus that words and concepts are bound together by an essential nature. Rather, words and sentences play varying roles in the different language games in which they are used, and it is this that determines what the meaning is within a given language game. Philosophers should cease analyzing words and concepts (with a view to discerning the individual essence of things), and should instead take an empirical stance and see how words and sentences are actually used in everyday life. (Note 10)

Wittgenstein's theory of meaning as use also suggests the logical distinctiveness of the many diverse language games which exist. Each language game has its own set of "rules" which governs the separate roles that words and sentences play within that game. And one cannot judge or justify the practices of one language game by 
another, because there is no shared framework in which such evaluation can proceed. When Wittgenstein talks about rules, he does not use 'rule' in the sense of something built into the nature of language or reality and being such that one's use of language must follow it. A given rule or interpretation of a sentence "hangs in the air along with what it interprets, and cannot give it any support." (Note 11) The agreement among people of what they say or do in actual cases is what determines whether a particular utterance or action accords with a given rule. Rather than to say that people agree in using language a certain way because they follow rules, it is more accurate to say that their agreement fixes the meaning of the rules and defines their content; in other words, human practice establishes what the rules are.

Given the distinctiveness of language games, each with its own set of rules determining how language and behavior is used and interpreted, there exists a strong tendency (according to Wittgenstein) for philosophy to stir up trouble for itself through the misuse of language. Philosophical problems often arise when an expression or utterance as it occurs in one language game is interpreted in accordance with the rules for its use in another language game. This happens when one tries to make language perform the same task in one language game that it (appropriately) performs in another. "Philosophical reflection has shown a fatal tendency to generate pseudo-problems by taking language out of its appropriate context and puzzling over how, if at all, it can be made to conform to criteria of intelligibility appropriate to contexts other than its own." (Note 12) Thus, for Wittgenstein, philosophical problems are solved by looking into the workings of our language, and that in such a way as to make us recognize those workings: in despite of an urge to misunderstand them. The problems are solved, not by giving new information, but by arranging what we have always known. Philosophy is a battle against the bewitchment of our intelligence by means of language. (Note 13)

All kinds of philosophical nonsense arise when one tries to make language do the same job in completely different modes of discourse, not conforming to the rules of its appropriate language game. In his Lectures on Religious Belief, Wittgenstein attempts to illustrate the manner in which such errors are committed with respect to religious discourse. It is to those lectures that we now turn.

\section{Wittgenstein on the Content of Religious Discourse: Three Key Features}

\subsection{Not Assessable Based on Evidence}

What bearing does Wittgenstein's notion of distinct language games and the use theory of meaning have on his discussion of religious belief? In the Lectures, one can discern three distinct characteristics that for Wittgenstein set apart the language game of religion from other common forms of discourse. The first is that religious beliefs are neither based on evidence nor open to rational verification. One claim that Wittgenstein repeatedly makes in the Lectures is that the language game of religion is logically distinct from other language games such as the language games of science or history. (Note 14) He contends that when people make religious utterances they are saying and doing something completely different from what the scientist or historian says or does. "Whatever believing in God may be, it can't be believing in something we can test, or find means of testing." (Note 15) Religious belief is not a matter of holding certain empirical truths, nor is it a matter of weighing the evidence for or against certain propositions; for to make it so would miss the whole point and "would in fact destroy the whole business." (Note 16) To take religious convictions and attempt to amass logical or empirical evidence in support of them (or to falsify them) would be to relegate them to the level of mere superstition. Wittgenstein's discussion of belief in a Last Judgment serves to illustrate this point:

Those who said: "Well, possibly it may happen and possibly not" would be on an entirely different plane. This is partly why one would be reluctant to say: "These people hold the opinion (or view) that there is a Last Judgement." 'Opinion' sounds queer. It is for this reason that different words are used: 'dogma,' 'faith'. We don't talk about hypothesis, or about high probability. Nor about knowing. In a religious discourse we use such expressions as: "I believe that so and so will happen," and we use them differently to the way in which we use them in science. (Note 17)

Wittgenstein's claim here is that to treat belief in a Last Judgement as a factual matter having a certain degree of plausibility or reasonability is to confuse the language game of religion with that of science. It is the worst kind of mistake to assume that utterances within the language game of religion can be treated in the same way as empirical and verifiable propositions found in other forms of discourse. Wittgenstein says that utterances in the language game of religion are both unreasonable and not-reasonable; they are unreasonable in the sense that certain apologists attempt to make them appear reasonable by foisting upon them the language of science and history, and they are not reasonable in the sense that they are not to be treated as a matter of reasonability at all. One does not argue for religious beliefs by appealing to logical reasoning or to what would be considered ordinary grounds for holding an opinion. To base religious claims on grounds and evidence appropriate only to 
propositions of non-religious language games is, for Wittgenstein, to destroy the very beliefs one holds and to rob them of their significance.

\subsection{Not Cognitively Significant}

A second defining characteristic of religious discourse is that such statements are not factually significant-- that is, they do not express matters of fact. Wittgenstein compares belief in a Last Judgement to one's belief that there is a German aeroplane flying overhead. If one were to respond in the latter case by saying, "Possibly, I'm not so sure," he would be speaking the same language game as the one who held the belief; but in the former case "you would say that there is an enormous gulf between us... It isn't a question of my being anywhere near him, but on an entirely different plane." (Note 18) This is closely related to the remarks Wittgenstein makes about the differences between believers and unbelievers and why they cannot be conceived of as "contradicting" one another. It is not simply a matter of religious believers differing in opinion from unbelievers as to whether certain things are the case or certain events will occur. Rather, believers mean something altogether different from unbelievers. They cannot contradict one another because they do not share the same "form of life." To illustrate, Wittgenstein offers the following example:

Take two people, one of whom talks of his behavior and of what happens to him in terms of retribution, the other one does not. These people think entirely differently. Yet, so far, you can't say they believe different things.

Suppose someone is ill and says: "This is punishment," and I say: "If I'm ill, I don't think of punishment at all." If you say: "Do you believe the opposite?"--you can call it believing the opposite, but it is entirely different from what we would normally call believing the opposite.

I think differently, in a different way. I say different things to myself. I have different pictures. (Note 19)

The views of the two people in Wittgenstein's illustration reveal a difference that runs deeper than the disagreement between believers and non-believers about the truth or falsity of certain religious propositions; rather, they are unable to say the same kinds of things to each other because they are playing different language games. The man who does not interpret his misfortunes in terms of divine punishment is not contradicting the believer who does, because the latter's belief is not about any matter of fact at all, and thus ipso facto is not about what can be true or false. If asked whether or not he believes in a Judgment Day in the sense in which religious people believe in it, Wittgenstein's reply is: "I wouldn't say 'No. I don't believe there will be such a thing.' It would seem to me utterly crazy to say this. And then I give an explanation: 'I don't believe in...', but then the religious person never believes what I describe." (Note 20) Wittgenstein's point in saying that he would not dispute the believer's claim seems to come down to this: to affirm the denial of any statement, say 'P', is to assert 'not-P'. But since to utter 'not-P' is to assert a factual claim, that in effect requires that ' $\mathrm{P}$ ' itself be a factual claim. Since 'P' is not a factual claim, one cannot truly assert 'not-P'. That is why Wittgenstein goes on to say that "the religious person never believes what I describe." If pressed to explain what he believes, Wittgenstein's description would indeed take the form of a factual claim. But religious beliefs contain no cognitive content; there is no question of their truth or falsity, because the question does not even apply. Religious statements make no claims that are empirically or factually significant whatsoever. Thus there is no possibility of contradicting the believer.

\subsection{Contains Affective Component}

A third crucial distinctive of religious discourse, according to Wittgenstein, is the affective element in religious belief-- how the convictions of the believer move his will and emotions. The "evidence" for the genuineness of one's belief, say, in the Last Judgment is whether or not it serves as a kind of rule which guides and regulates his whole life. The man who has the "firmest of all beliefs" is the man who "risks things on account of it which he would not do on things which are by far better established for him." (Note 21) Suppose there were people who could predict with amazing accuracy events in the far future, such as some sort of Judgment Day. Even if it were based on the best possible evidence, more convincing than anything else, yet it would not be a religious belief at all. On the other hand, a person unaware of such a forecast, but who "would fight for his life not to be dragged into the fire" and whose conviction of a Last Judgment "play[ed] the role of constantly admonishing him", would have an unshakable religious belief. (Note 22)

\section{Two Problems With Wittgenstein's Non-Cognitivist View of Religious Language}

\subsection{Not Supported by His General Theory of Meaning}

\subsubsection{How Language Games and Use Theory Properly Characterize Religious Statements}

For the sake of argument, let us concede the basic correctness of Wittgenstein's concept of language games, 
especially as it concerns the core claim that meaning is use. (Note 23) How well in fact does Wittgenstein's account of language games cohere with certain key claims he makes about the nature of religious discourse? My misgivings center around the first two features of Wittgenstein's characterization of religious language-- the denial that religious beliefs (and discourse) are verifiable or assessable for accuracy by means of evidence or argument, and the corresponding claim that such beliefs lack factual or cognitive significance. It is not my primary objective here to argue independently against these two claims Instead, what I want to argue is that these claims do not follow from any actual analysis of the language game of religion itself, but rather constitute an underlying presupposition Wittgenstein tacitly holds regarding (empirical) verifiability as a criterion for meaning. And if it is the latter which serves as the basis for Wittgenstein's assessment regarding the status of religious discourse, then his assessment rests on a feeble foundation. If we accept Wittgenstein's own account of the nature of language games outlined in the previous section, we will be led to conclude that at least some types of religious discourse involve claims purporting to be matters of fact, and in some cases perhaps even verifiable or assessable for truth in virtue of evidence. To understand any language game, Wittgenstein emphasizes that one must look at what people actually do with language and learn from that. (Note 24) Recall his comparison between comprehending the meaning of language in a given context and understanding a children's game by watching it being played and then inferring the rules inductively. The rules of a given form of discourse are not "embedded" in the nature of reality, but rather it is the actual usage of language over time that "fixes" the meaning of the rules. For Wittgenstein there is no substitute for this. In order to properly grasp the language game of religion, then, it follows that we must observe how religious language is used and expressed in everyday life.

Unfortunately for Wittgenstein, seriously adopting this approach to understanding language games seems to undermine his own characterization of religious language. For one historically common usage of religious language among human beings understands at least some religious assertions to be cognitively significant factual claims, some of which may be verifiable at least in principle. Here we may appeal to the historic Christian tradition, broadly construed, as a paradigm case for the study of the meaning of religious language. The interpretive history of the Bible and basic Christian doctrine serves as a clear illustration of a language game of religion at work, and one salient feature of this language game is the understanding, by the larger church as a whole, that many of the claims of both the Christian scriptures and the Church are factual in nature (and verifiable). Throughout the unfolding history of the Church, Christians have commonly understood written accounts of God's intervention in the world through miracles and other means as involving cognitive assertions with real historical and factual import. Consider, for example, the following sentences:

(1) God created the world.

(2) Yahweh spoke with Moses on Mount Sinai.

(3) Jesus of Nazareth turned water into wine and raised people from the dead.

(4) Each of us will continue to live as human beings in a conscious afterlife.

For over two millennia, the Judeo-Christian tradition and the church for the most part have understood such statements as purportedly factual claims having definite assertable truth conditions, in the same way that Wittgenstein would allow, say, that the following statements carry factual information:

(5) The universe originated from a big bang.

(6) Alexander the Great conquered Greece.

(7) My future physical death will permanently end my existence.

Not only would traditional Jews and Christians regard (1) - (4) as being on a par with (5), (6), and (7) in asserting matters of fact, but mainstream adherents of other world religions, such as Islam, as well as important schools of Hinduism and Buddhism, would also regard many of their important doctrinal tenets as conveying factual and sometimes verifiable information. Thus, for Wittgenstein to deny that any cognitive or purportedly factual elements are relevant to religious discourse is to ignore a primary function of certain central religious beliefs and claims as professed by the world's major religions.

\subsubsection{Wittgenstein's Unduly Restrictive Conception of Religious Belief}

Wittgenstein apparently is either unaware of how ordinary religious people themselves understand and use theological statements in everyday life, or else he denies the cognitive or matter of fact element of religious discourse on other grounds. Let's consider the former possibility. The examples to which Wittgenstein appeals in his discussion of religious language in $L R B$ do not accurately depict the way many religious believers typically 
think and talk. We can illustrate this by revisiting one of his main examples, briefly discussed in section II above. Wittgenstein contends that it would be strange for one to call his belief in a "Final Judgment" an opinion or view (in the sense of making some kind of cognitive assertion). But believers of various world religions, including many Christians throughout the history of the church, have clearly understood this doctrine to be a purportedly factual and even empirical claim which refers to some definite future spatio-temporal event. Further down in the same passage, in speaking of the allegedly historical claims of Christianity, Wittgenstein writes, "It has been said that Christianity rests on an historic basis... Here we have a belief in historic facts different from a belief in ordinary historic facts. Even, they are not treated as historical, empirical, propositions." (Note 25) But while it may be true that religious propositions differ in some ways from "ordinary" propositions about history, it does not at all follow that religious propositions are not, or cannot be, treated as historical, empirical, verifiable propositions. On the contrary, as I elaborated earlier, statements like (2) and (3) arguably are taken to be such propositions. From the standpoint of Wittgenstein's own method of understanding language games, including the language game of religion, to assert, as the believer may, certain theological claims which contain elements of empirical fact or other informative content is not to commit some logical mistake but rather to employ language in a manner that determines (in part) the nature and meaning of religious discourse itself. Analysis of the nature of the language game of religion implies that at least some religious or theological statements have cognitive content. Thus, Wittgenstein's insistence on the non-cognitive nature of religious discourse is rendered implausible by a proper application of his own method for understanding the workings of a language game.

Given how the language game of religion actually operates in some religious communities, there doesn't seem to be anything intrinsic to the nature of religious language that would preclude it from containing any factual or informational content. It is just not true that the propositions of religion have no affinity with the kinds of propositions used in the language games of science and history. Even granting Wittgenstein's contention that the language game of religion is logically distinct from those of history and science, we need not go as far as Wittgenstein does in accepting the further claim that religious discourse is categorically unlike the others with respect to the basic kind of meaning it has vis a vis cognitive content with determinate truth conditions, some of which are empirically verifiable. This comports well with what Wittgenstein says about language games in the Investigations. Language games have certain common features and relationships among them that "overlap and criss-cross", thus creating a kind of interdependence between all language games. (Note 26) So the logical distinctness of sets of language games does not mean that they have no elements in common. The language games of history on the one hand, and that of science on the other, may be logically distinct; yet they still have certain elements in common, such as cognitive significance and empirical verifiability. There seems to be nothing, then, inherent in the notion of logical distinctness itself that would bar religious language from sharing some of these same features.

If Wittgenstein thinks that all religious language functions in the way he suggests, as radically disconnected from the realms of science and history, then he has adopted an unfairly restrictive view of religious discourse and belief. This is not to deny that there are (and have been) theological schools of thought which interpret religious discourse as non-cognitive; and certainly many have claimed that "God talk" is essentially ineffable and beyond human grasp. (Note 27) But non-cognitivists in the realm of religion represent only one perspective on the nature and meaning of religious discourse. Such a viewpoint certainly does not solely define the way in which the language game of religion should be understood. Instead, perhaps we should view religious discourse as encompassing a family of distinct but related language games. The way in which certain "existential" or non-cognitivist theologians interpret theological expressions is importantly different from the way in which traditional believers understand them. Even within cognitivist approaches to religion, the meaning and use of key concepts such as 'God' varies from one religious perspective to another. To use Wittgenstein's terminology, these various distinct language games exhibit "family resemblances" with one another, bearing relationships among them that overlap and evince a kind of conceptual interdependence similar to that which connects the language games of the individual special sciences. If this is right, then rigorous application of Wittgenstein's views about language games and meaning should lead us to conclude that the function of some types of religious discourse serves to express claims which do indeed purport to be factual and even verifiable in nature.

\subsection{The Implausibility of an Independent Verification Criterion}

One obvious way to reconcile Wittgenstein's general view of meaning as use (espoused mainly in $P I$ ) with his characterization of religious belief (as preserved in $L R B$ ) is to refrain from treating the former as a fully sufficient condition which fixes the meaning of our beliefs and linguistic utterances. In the case of religion, the use and function of linguistic statements serves as a near sufficient condition for meaning which must also satisfy the further necessary condition that such statements be verifiable or assessable by evidence. This 
verifiability criterion should be seen as an independent necessary precondition on any purportedly cognitive or factual claim's having any meaning at all. This condition and the use theory together constitute a jointly sufficient condition for determining meaning. At this point, a defender of Wittgenstein may concede that while certain users of religious language intend their utterances to express matters of fact claims, the fact that such statements are not open to verification or evaluation by evidence precludes them from having any purportedly factual content attributed to them. Hence the defender of Wittgenstein can retain the use theory of meaning and yet at the same time insist that religious discourse is devoid of cognitive or factual content.

The downside to this suggestion is that it rests the weight of Wittgenstein's analysis of the meaning of religious discourse on something that bears no relation to the notion of language games or to the use theory at all-- namely, a controversial principle of verification. Problems with verificationist theories of (cognitive) meaning are well known. (Note 28) First, a statement's verifiability seems to presuppose that it already has cognitive meaning, for we must antecedently grasp the meaning of the statement before we are able to understand what counts as conclusive evidence or warrant for it. Moreover, it is notoriously difficult to specify a verifiability condition in such a way that it includes all and only those statements which intuitively capture what we take to be cognitively meaningful claims. In general, according to such a criterion, the meaning of a statement is given by specifying the evidential conditions that would conclusively justify or verify its assertion. Now, if we understand evidential conditions and verifiability to mean directly, empirically, and conclusively verifiable, then we certainly don't want to say that a statement $\mathrm{S}$ is verifiable if and only if there is a subject who is actually in a position to verify $\mathrm{S}$; or that $\mathrm{S}$ is verifiable if and only if there is a possible situation consistent with the state of the world up to the present in which a subject verifies S. For on those construals, statements referring to events or states of affairs which happened in the past or which happen in locations in which there are no observers would be unverifiable and hence not cognitively meaningful. Even if we weaken the modal condition to express something like "empirically and conclusively verifiable in principle", the criterion will not only (allegedly) render religious claims meaningless, but will end up ruling out many intuitively meaningful non-religious statements as well. Consider the formulation: $\mathrm{S}$ is verifiable if and only if there is a possible world which exemplify the actual laws of nature in which some subject directly and empirically verifies S. Statements about events or states of affairs which happened in the past or in remote locations are verifiable according to this definition, but other statements remain problematic. (5), for example, is not empirically or conclusively verifiable even in principle, according to the above formulation. Yet (5) is not only cognitively meaningful, many also think it is in fact true. Like (5), any statement which expresses a state of affairs which no conscious subject or scientific instrument can have empirical access to is incapable of being verified on this definition. Or consider the following series of statements, where $\mathrm{B}$ is an existing being and $\mathrm{E}$ is an event which occurs at some time:

(8) E occurred.

(9) There exists a being B.

(10) Some being or prior event caused E.

(11) B is a personal being (conscious, thinking, capable of action).

(12) A non-physical being or event caused $\mathrm{E}$.

(13) B is (or possesses) an immaterial soul.

(14) A purely physical being or event caused E.

(15) B is a purely physical being (a being lacking any non-physical parts or properties).

Arguably, only (8), (9), and perhaps (10) are verifiable given our verification condition. (Familiar arguments along Humean lines call (10) into question.) (11) is unverifiable because it is impossible for a third person observer to directly empirically and conclusively verify that B has the features of genuine consciousness and thought. (12) and (13) are unverifiable because, presumably, one cannot directly empirically verify the existence or occurrence of non-physical phenomenon. And (14) and (15) are similarly unverifiable because one cannot empirically verify that a given phenomenon possesses only physical or material properties. Yet statements (10) (15) are plausibly taken to be cognitively meaningful assertions with purportedly factual import. Suppose that the claim that a voice from the sky above Mt. Sinai could be heard speaking to Moses is verifiable and meaningful in the sense defined. The further claims that someone or something caused the voice-like sounds, or that God caused the voice-like sounds, or that a purely physical (human) being caused the voice-like sounds, are also cognitively meaningful assertions. Yet it is beyond anyone's ability to empirically or conclusively verify any of these assertions, even in principle, for the reasons just mentioned. Thus the verification criterion as presently articulated is too stringent a condition on meaning. 
Equally damaging to the verification criterion is the fact that at least some religious or theological claims $d o$ seem to satisfy the condition. Assertions such as (3) and (4), for example, are verifiable in principle and hence satisfy the condition. In order to make room for some of the other above statements (10) - (15) to be meaningful, one might be tempted to relax the direct-empirical-conclusive requirement on verifiability, so that we end up with an indirect and less restricted notion of verifiability as amenable to evidential support. One immediate problem with this proposal is that it is too weak and inclusive, rendering many religious and theological claims verifiable and thus cognitively meaningful, given that some degree of indirect evidence or argumentation can often be advanced on behalf of such claims. To my mind, then, the broad considerations of the foregoing paragraphs render the verifiability criterion problematic as a condition on meaning. To the extent that Wittgenstein's overall assessment of the nature of religious language rests on such a criterion, the plausibility of that assessment is called into question.

\section{Conclusion}

The basis of Wittgenstein's interpretation of religious language as non-cognitive (not expressing purported matters of fact) and not open to verification can be traced to two possible underlying sources in Wittgenstein's thought. One source is his suggestion in $L R B$ that an examination of the nature of religious discourse itself reveals that religious statements and beliefs are not verifiable or cognitively meaningful. We have seen, however, that given his related notions of language games and the use theory of meaning as espoused in $P I$, an actual analysis of religious language does not support such a conclusion. That led us in turn to consider a second possible source underlying Wittgenstein's view of religious language, namely that his assessment of the status of religious beliefs and discourse is guided by implicit acceptance of a verification criterion of meaning which he held independently of any analysis of language games. Unfortunately, this rationale for Wittgenstein's approach to religion renders it vulnerable to the weaknesses associated with the verification criterion itself. So on either of the above suggestions, I conclude that his bold assessment regarding the non-cognitive status of religious language and belief is unsubstantiated.

\section{References}

Braithwaite, R.B. (1968). An Empiricist's View of the Nature of Religious Beliefs. In John Hick, (Ed.), The Existence of God. New York: Macmillan.

Canfield, John. (1981). Wittgenstein: Language and World. Massachusetts: University of Massachusetts Press.

Clack, B.R. (1999). An Introduction to Wittgenstein's Philosophy of Religion. Edinburgh: Edinburgh University Press.

Hare, R.M. (1992). Essays on Religion and Education. New York: Oxford University Press.

Hudson, W. Donald. (1975). Wittgenstein and Religious Belief. New York: St. Martins Press.

Kenny, Anthony. (1973). Wittgenstein. Massachusetts: Harvard University Press.

Loux, Michael. (1998). Metaphysics. New York: Routledge.

Malcolm, Norman. (1993). Wittgenstein: A Religious Point of View? London: Routledge.

Mellor, D.H.. (1990). F.P. Ramsey: Philosophical Papers. Cambridge: Cambridge University Press.

Phillips, D.Z. (1970). Death and Immortality. London: Macmillan.

------. (1986). Primitive Reactions and the Reactions of Primitives. Religious Studies, 22(2), 165-180.

Wittgenstein, Ludwig. (1958). Philosophical Investigations. Edited by G. E. M. Anscombe. New York: Macmillan.

(1966). Lectures and Conversations on Aesthetics, Psychology, and Religious Belief. Edited by Cyril Barrett. Berkeley, CA: University of California Press.

\section{Notes}

Note 1. Norman Malcolm (1993) has argued that Wittgenstein espouses no such "theory", as his whole approach was anti-theoretical. For the sake of convenience, I will continue to use the word theory in this paper in the sense of a 'view' or 'position' as advocated by Wittgenstein.

Note 2. Ludwig Wittgenstein, Philosophical Investigations, 1958, sec. 7, p. 5. Hereafter cited as PI.

Note 3. PI, sec. 2, p. 3 .

Note 4. PI, sec. 7, p. 5. 
Note 5. PI, sec. 23, p. 12; sec. 563-567, p. 150.

Note 6. PI, sec. 23, p. 11.

Note 7. $P I$, sec. 67 , p. 32.

Note $8 . P I$, sec. 43, p. 20. For Wittgenstein, what is true of a word is also true of an expression or sentence. Thus, he says "Look at the sentence as an instrument, and its sense as its employment" (sec. 23, p. 12; emphasis mine). Similarly, another passage goes "What is this sense, then? Isn't there a verbal expression for this sense? But doesn't the fact that sentences have the same sense consist in their having the same use?" (sec. 20, p. 10).

Note 9. $P I$, sec. 11 , p. 6.

Note 10. PI, sec. 172, p. 70; sec. 116-117, p. 48.

Note 11. PI, sec. 198 , p. 80 .

Note 12. Hudson (1975, p.59).

Note 13. PI, sec. 109, p. 47. Elsewhere Wittgenstein says "The confusions which occupy us arise when language is like an engine idling, not when it is doing work" (sec. 132, p. 51). Wittgenstein seems to have in mind two kinds of mistakes which "bewitch our intelligence"; one involves confusion between what he calls the "surface grammar' and 'depth grammar' of a sentence (sec. 664, p.168), while the other involves being misled by using the wrong picture (sec. 115, p. 48).

Note 14. Ludwig Wittgenstein, Lectures \& Conversations on Aesthetics, Psychology, and Religious Belief, 1966, pp. 54-72 (edited by Cyril Barrett). Hereafter cited as $L R B$.

Note 15. $L R B$, p. 60.

Note 16. $L R B$, p. 56.

Note 17. $L R B$, p. 56-57.

Note 18. $L R B$, p. 53.

Note 19. $L R B$, p. 55.

Note 20. $L R B$, p. 55.

Note 21. $L R B$, p. 54.

Note 22. LRB, p. 56.

Note 23. This is an assumption that D.Z. Phillips argues we should not grant once we understand a fundamental problem with Wittgenstein's view of religious language. See Phillips (1986, pp. 168-170).

Note 24. PI, sec. 116, p. 48; see also sec. 654-655, p. 167.

Note 25. LRB, p. 57.

Note 26. $P I$, sec. 66-67, p. 31-32.

Note 27. See, for example, Hare (1964) and Braithwaite (1968). The discussion in Phillips (1970) also bears close affinity to the view here.

Note 28. See for, example, Loux (1998, pp. 285-293); and the collection of essays in Mellor (1990). 